\title{
Multifaceted effects of soluble human CD6 in experimental cancer models
}

To cite: Simões IT, Aranda F, Casadó-Llombart S, et al. Multifaceted effects of soluble human $\mathrm{CD} 6$ in experimental cancer models. Journal for ImmunoTherapy of Cancer 2020;8:e000172. doi:10.1136 jitc-2019-000172

- Additional material is published online only. To view please visit the journal online (http://dx.doi.org/10.1136/jitc2019-000172).

ITS and FA contributed equally.

ITS and FA are joint first authors.

Accepted 21 February 2020

Check for updates

(c) Author(s) (or their employer(s)) 2020. Re-use permitted under CC BY-NC. No commercial re-use. See rights and permissions. Published by BMJ.

For numbered affiliations see end of article.

\section{Correspondence to} Professor Francisco Lozano; flozano@clinic.cat

Dr Fernando Aranda, Immunoreceptors del Sistema Innat i Adaptatiu, Institut d'Investigacions Biomèdiques August Pi i Sunyer, Barcelona, Spain;

farandavega82@gmail.com

\author{
Inês T Simões, ${ }^{1}$ Fernando Aranda, ${ }^{1}$ Sergi Casadó-Llombart, ${ }^{1}$ \\ María Velasco-de Andrés, ${ }^{1}$ Cristina Català, ${ }^{1}$ Pilar Álvarez, ${ }^{2}$ \\ Marta Consuegra-Fernández, ${ }^{1}$ Marc Orta-Mascaró, ${ }^{1}$ Ramón Merino, ${ }^{3}$ \\ Jesús Merino, ${ }^{2}$ José Alberola-Ila, ${ }^{4}$ Gloria González-Aseguinolaza, ${ }^{5}$ \\ Esther Carreras, ${ }^{1}$ Vanesa Martínez, ${ }^{1}$ Francisco Lozano (D) ${ }^{1,6,7}$
}

\section{ABSTRACT}

Background CD6 is a lymphocyte surface co-receptor physically associated with the T-cell receptor (TCR)/CD3 complex at the center of the immunological synapse. There, CD6 assists in cell-to-cell contact stabilization and modulation of activation/differentiation events through interaction with CD166/ALCAM (activated leukocyte cell adhesion molecule), its main reported ligand. While accumulating evidence is attracting new interest on targeting CD6 for therapeutic purposes in autoimmune disorders, little is known on its potential in cancer. In an attempt to elucidate the in vivo relevance of blocking CD6mediated interactions in health and disease, we explored the consequences of expressing high circulating levels of a soluble form CD6 (sCD6) as a decoy receptor.

Methods High sCD6 serum levels were achieved by using transgenic C57BL/6 mice expressing human SCD6 under the control of lymphoid-specific transcriptional elements (shCD6LckE $\mu \mathrm{Tg}$ ) or wild type either transduced with hepatotropic adeno-associated virus coding for mouse sCD6 or undergoing repeated infusions of recombinant human sCD6 protein. Characterization of SCD6-induced changes was performed by ex vivo flow cytometry and functional analyses of mouse lymphoid organ cells. The in vivo relevance of those changes was explored by challenging mice with subcutaneous or metastatic tumors induced by syngeneic cancer cells of different lineage origins.

Results Through a combination of in vitro and in vivo studies, we show that circulating SCD6 expression induces defective regulatory $T$ cell (Treg) generation and function, decreased CD166/ALCAM-mediated tumor cell proliferation/migration and impaired galectin-induced T-cell apoptosis, supporting the fact that SCD6 modulates antitumor lymphocyte effector function and tumorigenesis. Accordingly, sCD6 expression in vivo resulted in delayed subcutaneous tumor growth and/or reduced metastasis on challenge of mice with syngeneic cancer cells. Conclusions Evidence is provided for the disruption of CD6 receptor-ligand interactions as a feasible immunomodulatory approach in cancer.

\section{BACKGROUND}

Immunomodulation is gaining ground for the treatment of several disorders involving either excessive (eg, autoimmune) or defective (eg, cancer) immune responses by targeting the on/off molecular switches that set the intensity and/or duration of ongoing immune responses. These include co-stimulatory (eg, CD28) or inhibitory (eg, CTLA-4) membrane-bound lymphocyte receptors present at the immunological synapse (IS), a supramolecular activation complex at the interface between antigen-presenting cells (APCs) and T cells. ${ }^{1}$

CD6 is a lymphocyte surface receptor physically associated with the T-cell receptor (TCR)/CD3 complex at the center of the IS, with roles in the stabilization of this structure and in $\mathrm{T}$ cell activation and differentiation signaling. ${ }^{2}$ CD6 variants have been identified as susceptibility or disease modifier markers for multiple sclerosis, inflammatory bowel disease, Behçet's disease, psoriasis, and rheumatoid arthritis, and an anti-CD6 monoclonal antibody (mAb) is now under therapeutic consideration in some autoimmune disorders. ${ }^{3}$ These reports suggest that CD6 is a suitable candidate for immunomodulatory targeting.

CD6 is expressed on thymocytes and mature $\mathrm{T}$ cells, a subset of $\mathrm{B}$ (B1a) and natural killer (NK) cells, and on certain hematopoietic precursors and brain regions. ${ }^{2}$ Its extracellular region is composed of three tandem scavenger receptor cysteine-rich (SRCR) domains, from which the membraneproximal domain (D3) binds to the aminoterminal domain (D1) of activated leukocyte cell adhesion molecule (ALCAM), a member of the immunoglobulin (Ig) superfamily of cell adhesion molecules present on activated lymphocytes, professional APCs (dendritic cells, macrophages and B cells), thymic epithelial cells, endothelial cells, and brain cells. ${ }^{4}$ Additional interactions mediated by the CD6 ectodomain include galectin (Gal)-1 and Gal-3, conserved bacterial cell 
wall components, and more recently, CD318/CDCP1 (CUB domain-containing protein 1). ${ }^{56}$ The intracellular domain of CD6 lacks intrinsic catalytic activity but can be phosphorylated by Ser/Thr and Tyr kinases to mediate signal transduction. The signaling pathway used by CD6 is only partially known and involves activation of mitogenactivated protein kinases, and recruitment of intracellular effectors such as Syntenin-1, GADS/SLP-76 and TSAd. ${ }^{2}$

In addition to its co-stimulatory lymphocyte receptor function, data from $c d 6$ knockout $\left(c d 6^{-}\right)$mice reveal that CD6 downregulates TCR signaling in immature thymocytes, with an impact on peripheral effector/memory $\left(\mathrm{T}_{\mathrm{EM}}\right)$ and regulatory (Treg) $\mathrm{T}$ cell function. ${ }^{7}$ Recent in vitro evidence from $c d 6^{--}$mice shows that CD6 is also a negative regulator of activation and activation-induced cell death for peripheral T cells. ${ }^{8}$

As for a large number of other lymphocyte surface receptors, low circulating levels (picomolar) of soluble human CD6 (shCD6) generated mainly by proteolytic cleavage on TCR/CD3-mediated activation can be detected in normal serum, and in serum from patients with systemic autoimmune or inflammatory disorders. ${ }^{9-11}$ Recombinant shCD6 inhibits T-cell proliferation in vitro to an extent comparable with CD6-blocking antibodies or recombinant ALCAM-Fc protein, suggesting that CD6 and ALCAM are a key receptor-ligand pair in APC-T-cell interactions. $^{12-14}$

To gain further insight into the role of CD6 in immune responses, we studied the effects of increasing the serum concentration of shCD6 in mice under normal and disease-inducing conditions. We hypothesized that shCD6 could abolish CD6 function by acting as a decoy receptor in mice and blocking homophilic and/ or heterophilic interactions between CD6 ligands. Indeed, the same interface of ALCAM is involved in heterophilic (CD6-ALCAM) and homophilic (ALCAMALCAM) interactions, where heterophilic interactions show higher affinity and better conservation between mouse and human. ${ }^{15} 16$ To test our hypothesis, we generated a new transgenic mouse line (shCD6LckE $\mu \mathrm{Tg}$ ) that expresses shCD6 under the control of lymphoid-specific transcriptional elements active from early $\mathrm{T}$ and $\mathrm{B}$ cell developmental stages. ${ }^{17}$ Transgenic expression of solubilized receptors (eg, CTLA-4, IL-6R, TNFRp55, CD14, VEGFR-3 or CR1/CD35) has proved useful to understand their in vivo function and therapeutic potential. ${ }^{18-22}$ This strategy also favors eventual translation to the clinical practice through established and approved protein delivery systems.

The shCD6LckE $\mu$ Tg mice exhibited delayed growth of non-orthotopic tumors, which was reproduced in wild-type (WT) mice by infusion of recombinant shCD6 protein. In vitro studies showed that mechanisms operating at the level of lymphocyte effector function and tumorigenicity were engaged in the presence of shCD6. This provides the first proof-of-concept therapeutic potential of shCD6 in cancer.

\section{MATERIALS AND METHODS}

\section{Animals}

Transgenic shCD6E $\mu$ LckTg mice were generated in C57BL/6N background. Non-transgenic (NonTg) mice used for comparative purposes came from the same common heterozygous ancestors as the shCD6E $\mu \mathrm{LckTg}$ mice and were kept under the same housing conditions as the latter. The shCD6LckE $\mu \mathrm{Tg}$ mice were viable and fertile, and their lifespan and behavior were equivalent to those of NonTg mice. WT C57BL/6N mice were purchased from Charles River Laboratories. All animals were kept under specific pathogen-free (SPF) conditions and used at 7-8 weeks of age.

\section{Cells and proteins}

Spleen, inguinal lymph nodes (LNs) and thymus cell suspensions were obtained by pressing with a syringe plunger through a $40 \mu \mathrm{m}$ cell strainer (Biologix Research), and erythrocyte-depleted by using red blood cell lysis buffer (eBioscience).

C57BL/6-derived B16.F0, MCA205, EL-4, and RMA-S tumor cell lines were obtained from Dr R. Alemany (Institut Català d'Oncologia, L'Hospitalet de Llobregat, Spain) and Dr P. Lauzurica (Instituto de Salud Carlos III, Madrid, Spain). B16.F0 cells were grown in Dulbecco's Modified Eagle medim (DMEM, Invitrogen) supplemented with $10 \%$ fetal bovine serum (FBS) and $100 \mathrm{IU} /$ $\mathrm{mL}$ penicillin/streptomycin. MCA205, EL-4, and RMA-S cells were grown in Rosswell Park Medium Institut (RPMI) 1640 medium (Lonza) supplemented with 10\% FBS, 10 $\mathrm{mM}$ HEPES, $2 \mathrm{mM}$ glutamine, $1 \mathrm{mM}$ sodium pyruvate and $100 \mathrm{IU} / \mathrm{mL}$ penicillin/streptomycin.

Production and purification of endotoxin-free purified recombinant shCD6 and shCD5 proteins (in PBS with 10\% glycerol, $\mathrm{pH}$ 7.4) from SURE CHO-M cell line clones was done following previously reported methods. ${ }^{23}$ Human (HSA) and bovine (BSA) serum albumin were from Sigma-Aldrich.

\section{Generation of shCD6LckE $\mu$ transgenic mice}

The codon-optimized cDNA sequence encoding the whole ectodomain of human CD6 (GenBank X60992.1) from the initiation M1 to R373 was synthesized at GenScript (New Jersey, USA) and cloned into the BamHI site of the p1026x vector (kindly provided by Dr R.M. Perlmutter), just downstream of the lck proximal promoter and the Ig heavy chain enhancer $(\mathrm{E} \mu) .{ }^{17}$ Transgenic mice were generated at PolyGene (Rümlang, Switzerland) by injecting the purified NotINotI fragments into zygotes from superovulated C57BL/6N female mice mated to C57BL/6N breeder males (Charles River). Injected zygotes were cultured overnight and transferred into pseudopregnant $\mathrm{B}_{6} \mathrm{xCBAF}_{1}$ females (Charles River). PCR screening for transgene integration identified 2 positive out of 14 pups. One of them was bred to homozygosity and maintained in parallel with WT mice from the same original cross. Tail genomic DNA was extracted by the KAPA Mouse Genotyping Kit (Kapa Biosystems) and subjected to PCR amplification with primer pairs specific 
for the CD6 ectodomain (Fw 5'-ACC TGA CCA GCT CAA CAC-3' and Rv 5'-GTC ATC GCA CAC TGA TCC-3') and the MHC class II invariant Ii chain (Fw $5^{\prime}$-TCA CTC AAG GCA ACC TTC CTGC-3' and Rv 5'-CGA CCT CAT CTC TAA CCA TGA ACAG-3'), resulting in 495 bp and $150 \mathrm{bp}$ fragments, respectively.

\section{Construction and production of recombinant adeno- associated virus (AAV)}

Construction and production of recombinant AAV8 virus expressing soluble mouse CD6 (AAV-smCD6) or luciferase (AAV-Luc) proteins under the control of a chimerical liver-specific (EalbAAT) promoter was carried out as previously reported. ${ }^{23}$

\section{ELISA assays}

The plasma levels of shCD6 and smCD6 were quantified with the human soluble CD6 PicoKine ELISA Kit (Boster Bio) and the DuoSet mouse CD6 kit (R\&D Systems), respectively, following manufacturer's instructions.

\section{Flow cytometry analyses}

Surface stainings were performed by blocking cells in phosphate-buffered saline (PBS) plus 10\% FBS for $30 \mathrm{~min}$ at $4^{\circ} \mathrm{C}$ with rat anti-mouse $\mathrm{CD} 16 / 32$ (2.4G2; Mouse BD Fc Block) and further incubation with the following labeled $\mathrm{mAb}$ and appropriate isotype controls: biotin-labeled anti-BP-1 (6C3, eBioscience); fluorescein isothiocyanate (FITC)-labeled anti-CD4 (RM4-5, Tonbo Biosciences), antiB220 (Ra3-6B2, Tonbo), anti-CD44 (IM7, BD Biosciences), and anti-CD24 (M1/69, BD Pharmingen); phycoerythrinlabeled anti-IgD (11-26, SouthernBiotech), anti-NK1.1 (PK136, BD Biosciences), anti-CD8 (53-6.7, BioLegend), anti-FoxP3 (3G3, Tonbo), anti-CD19 (1D3, Tonbo), and anti-ALCAM (eBioALC48, eBiosciences); PerCP-Cy5.5labeled anti-CD3 (145-2 C11, Tonbo), anti-CD8 (53-6.7, Tonbo), anti-CD44 (IM7, Tonbo), and streptavidin (BD Biosciences); allophycocyanin-labeled anti-CD3 (145-2 C11, Tonbo), anti-CD62L (MEL-14, Tonbo), anti-CD3e (145-2 C11, Tonbo), anti-IgM (II/41, eBioscience), anti-LAP (TW7-16B4, Biolegend), and anti-CD25 (PC61.5, eBiosciences); APC-Cy7-labeled anti-CD25 (PC61, BD Pharmingen); Pe-Cy7-labeled anti-CD5 (53-7.3, eBiosciences), anti-CD19 (1D3, Tonbo), and anti-CD4 (GK1.5, BioLegend); violetFluor 450-labeled anti-B220 (RA3-6B2, Tonbo) and anti-CD8 (53-6.7, Tonbo). FoxP3 intracellular staining was performed with the phycoerythrin-labeled anti-mouse/rat Treg Staining Kit (eBioscience), according to the manufacturer's instructions. Data were analyzed in a FACSCanto II flow cytometer (Becton Dickinson) using FlowJo software (Tree Star).

\section{Bromodeoxyuridine incorporation and Treg suppression assays}

Detection of in vivo proliferating cells with bromodeoxyuridine (BrdU) was performed as reported elsewhere. ${ }^{24}$ Treg isolation and suppressive activity assays were performed as previously reported. ${ }^{25}$

\section{$\mathrm{CD4}^{+} \mathrm{T}$ cell polarization assays}

Naïve CD $4^{+} \mathrm{T}$ cells $\left(\mathrm{CD} 4^{+} \mathrm{CD} 25^{-\mathrm{CD}} 62 \mathrm{~L}^{\mathrm{hi}} \mathrm{CD} 44^{\mathrm{lo}} ; 1 \times 10^{5}\right)$ from $\mathrm{C} 57 \mathrm{BL} / 6 / \mathrm{J}$ spleens sorted with Dynabeads Untouched Mouse CD4 cells Kit (Thermo Fisher Scientific) were activated for 72 hours in triplicate in 96-well U-bottom plates with coated anti-CD3 $(2 \mu \mathrm{g} / \mathrm{mL})$ plus soluble anti-CD28 $(0.5 \mu \mathrm{g} / \mathrm{mL}) \mathrm{mAb}$ under standard Treg, Th1, Th2 or Th17 polarization conditions (see https:// BioLegend.com/en-us/technical-protocols) in the presence or absence of shCD6 protein $(0-10 \mu \mathrm{g} / \mathrm{mL})$. Cells were stained for surface CD4 (RM4-5) and intracellular FoxP3 (3G3) expression for Treg analysis. For Th1, Th2 and Th17 analysis, cells were restimulated for 5 hours with phorbol myristate acetate (PMA, $80 \mathrm{nM}$ ) and ionomycin $(1 \mu \mathrm{g} / \mathrm{mL})$ in the presence of $2 \mu \mathrm{M}$ monensin followed by surface CD4 and intracellular IFN- $\gamma$ (XMG1.2, Tonbo), IL-4 (11B11, BD Biosciences) or IL-17 (eBio17B7, eBioscience) staining, respectively.

\section{In vivo tumor cell growth and metastasis assays}

Assessment of local subcutaneous growth and lung metastatization of syngeneic tumor cells in vivo was performed as reported elsewhere. ${ }^{25} 26$

\section{Quantitative real-time PCR analyses}

Total mRNA $(0.5 \mu \mathrm{g})$ extracted from cell lines by using the PureLink RNA Mini Kit (Ambion, Life Technologies) was retrotranscribed into cDNA by using the highcapacity cDNA Kit (Life Technologies). Galectin mRNA levels were assessed by quantitative real-time PCR (qRTPCR) analysis (Taqman Fast Universal PCR Master Mix; Life Technologies) using a 7900HT fast real-time PCR System (Applied Biosystems) and the following Taqman probes (Thermo Fisher): Gal-1 (Mm00839408_g1), Gal-3 (Mm00802901_m1) and GAPDH (Mm99999915_g1). Galectin mRNA expression was adjusted by GAPDH expression as $2^{\Delta \mathrm{Ct}}$, where $\Delta \mathrm{Ct}=\mathrm{Ct}(\mathrm{GAPDH})-\mathrm{Ct}$ (gene of interest).

\section{Galectin-induced apoptosis assays}

C57BL/6J splenocytes $\left(1 \times 10^{5}\right)$ activated for 72 hours in 12-well plates with coated anti-CD3 (145-2 C11; $1 \mu \mathrm{g} / \mathrm{mL}$, Tonbo) plus soluble anti-CD28 (37.51; $5 \mu \mathrm{g} / \mathrm{mL}$, Tonbo) $\mathrm{mAb}$ were further suspended in FBS-free RPMI medium for $30 \mathrm{~min}$ at $37^{\circ} \mathrm{C}$ in the presence of $100 \mu \mathrm{g} / \mathrm{mL}$ of endotoxinfree glutathione S-transferase (GST) and fusion GST-Gall and GST-Gal3 proteins, produced and purified as reported elsewhere. $^{5}$

\section{Apoptosis assays}

Apoptotic cells were detected using the Annexin V-FITC apoptosis detection kit following the manufacturer's instructions (ImmunoStep).

\section{In vitro tumor cell growth and migration assays}

Tumor cell proliferation was monitored as reported elsewhere. ${ }^{27}$ Wound healing technique was used to assess tumor cell migration. ${ }^{28}$ 


\section{Statistical analyses}

Statistical analyses and data representation were performed with GraphPad Prism V.6 Software.

\section{RESULTS}

\section{Generation and immunophenotypical analysis of} shCD6LckE $\mu \mathrm{Tg}$ mice

CD6-mediated interactions were investigated in vivo by generating a transgenic mouse line (shCD6LckE $\mu \mathrm{Tg}$ ) expressing the soluble ectodomain of human CD6 (shCD6) in a C57BL/6N background. The transgene was under control of lymphocyte-specific transcriptional elements (lck proximal promoter and $\mathrm{E} \mu$ enhancer) (figure 1A), which drive shCD6 expression mainly to primary and secondary lymphoid organs. Identification of transgenic mice was performed by PCR amplification of a 495 bp fragment corresponding to the human CD6 ectodomain (figure 1B), and ELISA measurement of plasma shCD6 levels, which yielded $79.2 \pm 19.7$ and $38.7 \pm 6.3 \mathrm{ng} /$ $\mathrm{mL}$ for homozygous and heterozygous mice, respectively (figure 1C).

Primary lymphoid organ analyses (online supplementary figure S1A and S1B) showed no differences between shCD6LckE $\mu$ Tg and NonTg mice regarding thymus and bone marrow total cell numbers, as well as the frequency of all B-cell developmental subsets (figure 1D, left and middle). In contrast, shCD6LckE $\mu$ Tg presented significantly higher fractions of double-negative (DN) and CD8 single-positive (CD8SP) thymocytes (figure 1D, right), suggesting a role for CD6-mediated interactions in T cell but not B-cell developmental process.

The analysis of peripheral lymphoid organs revealed decreased total cell numbers in spleen and LN from shCD6LckE $\mu$ Tg mice compared with NonTg controls (figure 1E, left). Annexin $\mathrm{V}$ and 7-AAD staining of total spleen and LN cells showed no differences between shCD6LckE $\mu \mathrm{Tg}$ and NonTg mice regarding cell apoptosis levels (figure $1 \mathrm{E}$, right). In vivo BrdU-incorporation assays revealed a decrease in the percentage of $\mathrm{BrdU}^{+}$cells in spleen and LN from shCD6LckE $\mu$ Tg mice (figure 1F). A more detailed analysis (online supplementary figure S1C and S1E) showed that lower BrdU incorporation affected the B cell $\left(\mathrm{CD} 19^{+}\right)$compartment in both spleen and LN. These results indicate that a lower proliferative capacity of $\mathrm{B}$ cells is behind the reduced cellularity found in the peripheral lymphoid organs of shCD6LckE $\mu \mathrm{Tg}$ mice.

Another consistent finding in peripheral (spleen and LN) but not central (thymus) lymphoid organs from shCD6LckE $\mu$ Tg mice was the presence of decreased percentages of $\mathrm{CD} 25^{+} \mathrm{FoxP}^{+}$cells within the $\mathrm{CD} 4^{+}$subset (Treg) (figure 2A and online supplementary figure S2). Moreover, Treg cells from shCD6LckE $\mu \mathrm{Tg}$ mice showed lower expression levels of latency-associated peptide (LAP) (figure 2B), a well-known surface marker directly correlating with Treg functionality. ${ }^{29}$ In agreement with this finding, in vitro suppression assays confirmed that $\mathrm{CD} 4^{+} \mathrm{CD} 25^{+/ \mathrm{hi}} \mathrm{T}$ cells (Treg) from shCD6LckE $\mu \mathrm{Tg}$ mice exhibited lower suppressive activity on activated $\mathrm{CD} 4^{+} \mathrm{CD} 25^{-} \mathrm{T}$ cells (Tconv) at high Tconv:Treg (8:1) ratios than those from NonTg mice (figure 2C).

The putative effects of shCD6 on T cell polarization were further explored in vitro by culturing naive $\mathrm{CD} 4^{+} \mathrm{T}$ cells $\left(\mathrm{CD} 4^{+} \mathrm{CD} 25 \mathrm{CD}^{-} 2^{\mathrm{hi}}{ }^{\mathrm{CD}} 44^{\text {lo }}\right)$ from WT mice under Th1, Th2, Th17 and Treg cell polarization conditions in the presence of increasing doses of shCD6 (0.1, 1 and $10 \mu \mathrm{g} / \mathrm{mL}$ ). As illustrated in figure 2D, dose-dependent reduction in the percentage of polarized Treg but not Th1, Th2 or Th17 cells was observed. Moreover, a reduction in the surface expression levels of LAP was observed in in vitro polarized Treg cells in the presence of shCD6 $(10 \mu \mathrm{g} / \mathrm{mL})$ (figure 2E), pointing to a role for shCD6 on the reduced frequency and/or functionality of peripheral Treg cells in shCD6LckE $\mu$ Tg and shCD6-treated mice.

To assess the in vivo functional relevance of our immunophenotypical observations, shCD6LckE $\mu$ Tg mice were challenged by subcutaneous injection with syngeneic cancer cells. As shown in figure 3 (left), growth of melanoma B16.F0 tumor cells was slower in shCD6LckE $\mu \mathrm{Tg}$ mice than in NonTg controls. Tumor weight at the end of the follow-up period (day 20) was not statistically significant. Similar analyses performed with syngeneic tumor cells of fibrosarcoma (MCA205) and lymphoma (RMA-S) origin also showed reduced tumor growth and weight for shCD6LckE $\mu$ Tg mice (figure 3, middle and right), indicating an enhanced and non-cell lineage-specific antitumor response.

\section{Infusion of shCD6 to WT mice induces immunophenotypical changes in peripheral lymphoid organs and reduced growth of subcutaneously implanted syngeneic cancer cells}

In order to rule out transgenesis artifacts, immunophenotypical analyses were performed following repeated administration of shCD6 protein $(1.25 \mathrm{mg} / \mathrm{kg}$, everyother-day intraperitoneal for 15 days) to WT mice. Thymus analyses showed no differences between shCD6treated and vehicle-treated mice regarding total cell numbers (figure 4A) and the frequency of T-cell developmental subsets (online supplementary figure S3). In the periphery, statistically significant reductions of total cell numbers were detected in spleen but not LN from shCD6-treated mice (figure 4A). The percentage of $\mathrm{CD}^{2} 5^{+} \mathrm{FoxP}^{+}$cells within the $\mathrm{CD} 4^{+}$subset was also found significantly decreased in LN but not spleen samples from shCD6-treated mice (figure 4B). Thus, infusion of shCD6 on alternate days for a limited period of time reproduced some of the immunophenotypical changes observed in shCD6LckE $\mu$ Tg.

To investigate whether infusion of shCD6 protein also delays tumor growth in vivo, WT mice were subcutaneously implanted with B16.F0 cells and then intraperitoneally infused with $1.25 \mathrm{mg} / \mathrm{kg}$ shCD6 every-other-day from the day of tumor implantation. As illustrated in figure 5, shCD6-treated mice showed a statistically significant reduction in B16.F0 tumor cell growth compared with vehicle-treated mice. Similar results were observed when 

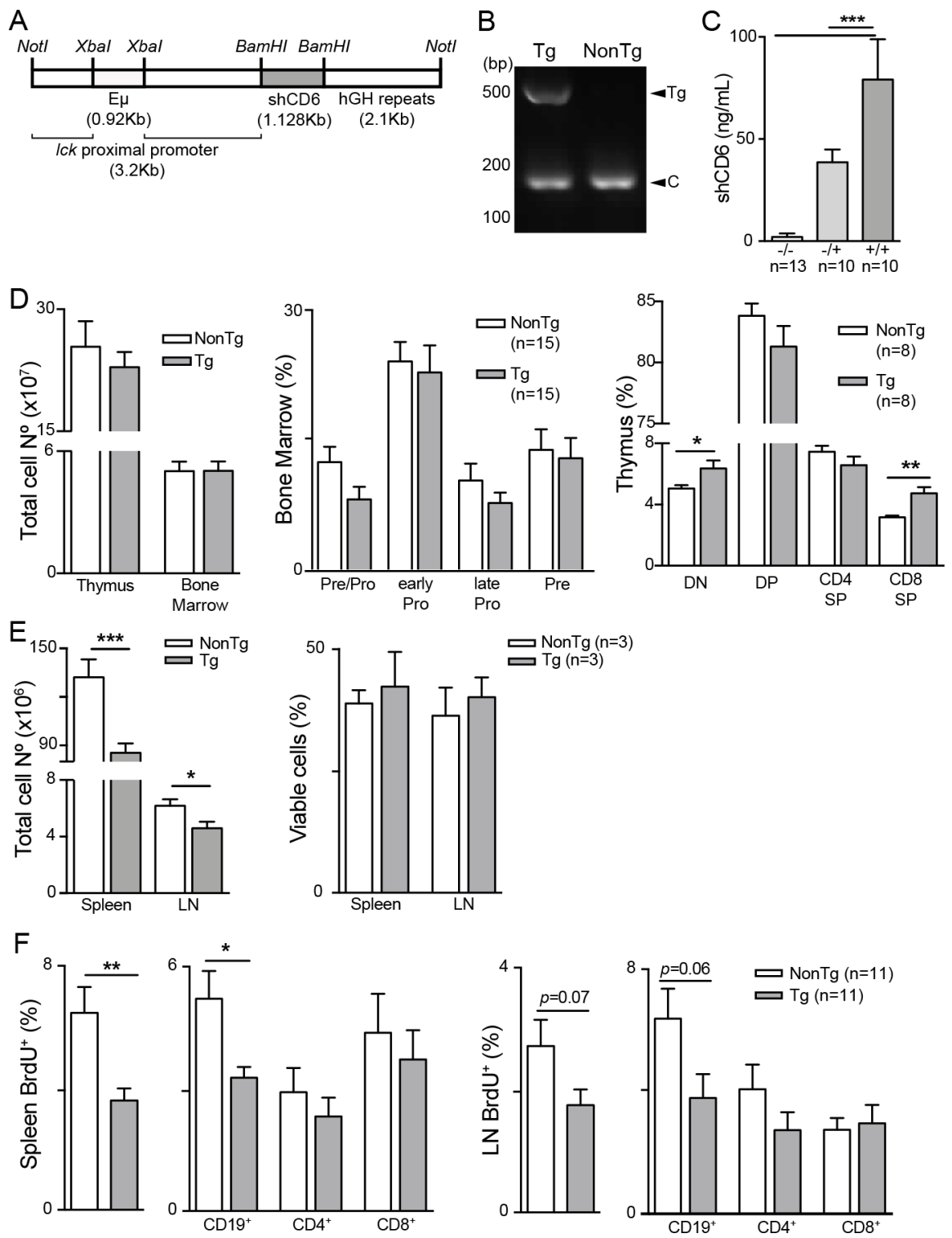

Figure 1 Generation and immunophenotypical characterization of shCD6LckE $\mu \mathrm{Tg}$ mice. (A) Schematic representation of the transgene coding for soluble human CD6 (shCD6). (B) PCR screening of genomic DNA from homozygous shCD6LckE $\mu$ Tg and non-transgenic (NonTg) mice. Bands correspond to transgene (Tg) and internal PCR control (C). (C) ELISA quantification of plasma shCD6 levels from NonTg (-/-), and heterozygous (-/+) and homozygous (+/+) shCD6E $\mu \mathrm{LckTg}(\mathrm{Tg})$ mice. Represented are cumulative data from two independent experiments, expressed as mean $\pm S E M$. ${ }^{* \star *} p<0.001$; two-tailed Student's t-test. (D) Immunophenotypical characterization of primary lymphoid organs from shCD6LckE $\mu \mathrm{Tg}$ mice. Left: total lymphoid cell numbers from thymus and bone marrow of shCD6LckE $\mu \mathrm{Tg}$ ( $n=21$ and $n=13$, respectively) and NonTg ( $n=15$ and $n=16$, respectively) mice. Middle: percentage of CD24 ${ }^{\text {low } B P 1} 1^{-}$(pre-pro B cells), CD24 ${ }^{+} \mathrm{BP} 1^{-}$(early pro B cells), $\mathrm{CD} 24^{+} \mathrm{BP} 1^{+}$(late pro B cells) and $\mathrm{CD} 24^{\text {high }} \mathrm{BP}^{+}$(pre B cells) within gated $\mathrm{CD} 43^{+} \mathrm{B}_{220^{+}}$bone marrow cells from shCD6LckE $\mu \mathrm{Tg}$ and NonTg mice. Right: percentage of $\mathrm{CD}^{-} \mathrm{CD} 8^{-}(\mathrm{DN}), \mathrm{CD}^{+} \mathrm{CD} 8^{+}(\mathrm{DP}), \mathrm{CD}^{+} \mathrm{CD} 8^{-}(\mathrm{CD} 4 \mathrm{SP})$ and $\mathrm{CD} 4^{-} \mathrm{CD} 8^{+}$(CD8SP) thymocytes from shCD6 $\mathrm{LckE} \mu \mathrm{Tg}$ and NonTg mice. Represented are cumulative data from at least two independent experiments, expressed as mean \pm SEM. ${ }^{*} \mathrm{p}<0.05$; ${ }^{* *} \mathrm{p}<0.01$; two-tailed Student's t-test. (E) Immunophenotypical characterization of secondary lymphoid organs from shCD6LckE $\mu$ Tg mice. Left: total lymphoid cell numbers in spleen, and lymph node (LN) from shCD6LckE $\mu T g$ ( $n=50$ and $n=23$, respectively) and NonTg ( $n=61$ and $n=28$, respectively) mice. Right: percentage of viable cells (7AAD AnnexinV) from spleen and LN of shCD6LckE $\mu \mathrm{Tg}$ and NonTg mice. One of two independent experiments is shown. (F) In vivo Bromodeoxyuridine (BrdU)-incorporation assays in secondary lymphoid organs from shCD6LckE HTg mice. Percentage of spleen (left) and LN (right) $\mathrm{BrdU}^{+}$lymphoid cells represented as total cells and as cells gated on $\mathrm{CD} 19^{+}, \mathrm{CD} 4^{+}$and $\mathrm{CD} 8^{+}$. Represented are cumulative data from at least two independent experiments, expressed as mean $\pm S E M$. ${ }^{*} p<0.05 ;{ }^{* \star} p<0.01 ;{ }^{\star \star \star} p<0.001$; two-tailed Student's ttest. 

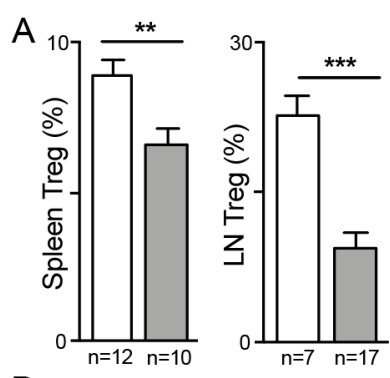

D
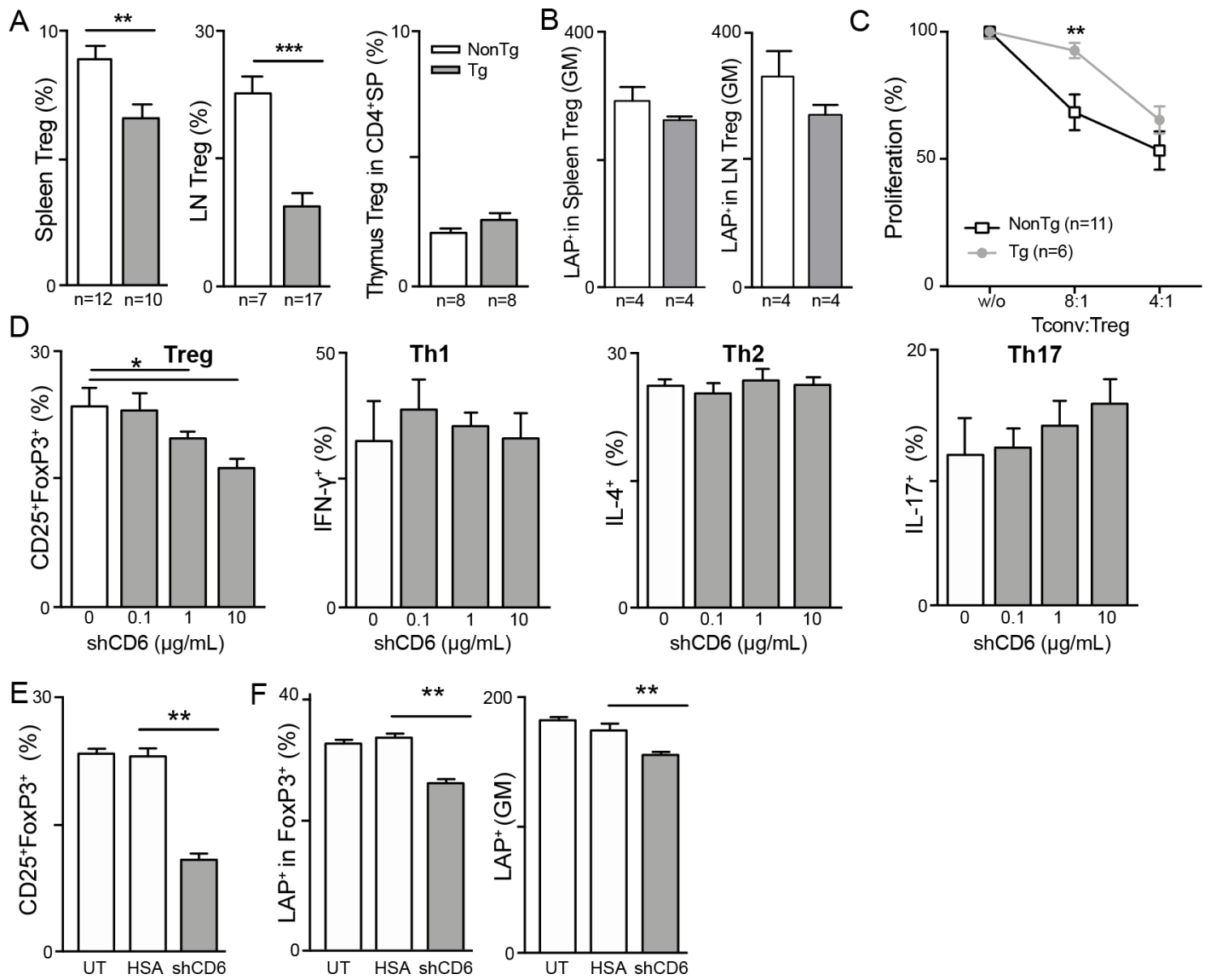

Figure 2 Effects of soluble human CD6 (shCD6) on the frequency and functionality of Treg cells. (A) Percentage of $\mathrm{CD}^{2} 5^{+} \mathrm{FoxP}^{+}$in $\mathrm{CD}^{+}$gated cells (Treg) from spleen, lymph node $(\mathrm{LN})$ and thymus of shCD6LckE $\mu \mathrm{Tg}$ and non-transgenic (NonTg) mice. (B) Geometric mean fluorescence intensity (GM) for latency-associated peptide (LAP) expression on spleen and LN Treg cells (defined as in a) from shCD6LckE $\mu$ Tg and NonTg mice. (C) Percentage of proliferation of CD4 ${ }^{+} \mathrm{CD}_{25}$ (Tconv) cells from NonTg mice stimulated for 72 hours with anti-CD3 mAb plus anti-CD28 monoclonal antibody (mAb) in the absence (w/o) or presence of different ratios of CD4 $4^{+} \mathrm{CD} 25^{+}$(Treg) cells from shCD6LckE $\mu \mathrm{Tg}$ or NonTg mice. (D) Sorted naïve $\mathrm{CD} 4^{+} \mathrm{CD} 25^{-}$ CD62 $\mathrm{L}^{\mathrm{hi}} \mathrm{CD} 44^{\text {lo }}$ splenocytes $\left(1 \times 10^{5}\right)$ from C57BL/6J $(\mathrm{n}=5)$ were activated in triplicate for 72 hours with anti-CD3 $(2 \mu \mathrm{g} / \mathrm{mL})$ and anti-CD28 $(0.5 \mu \mathrm{g} / \mathrm{mL}) \mathrm{mAbs}$ under Treg, Th1, Th2, and Th17 polarization conditions, all in the presence or absence of different amounts of shCD6 $(0,0.1,1$ and $10 \mu \mathrm{g} / \mathrm{mL})$. Percentage of Treg, Th1, Th2, and Th17 in CD4 ${ }^{+}$cells as deduced from intracellular FOXP3, IFN- $\gamma$, IL-4 and IL-17 co-staining, respectively, are represented as mean $\pm S E M .{ }^{* *} \mathrm{p}<0.01$; ${ }^{* * *} \mathrm{p}<0.001$; unpaired t-test with Welch's correction. (E) In vitro polarized Treg cells generated as in (D) and cultured alone (UT) or in the presence of 10 $\mu \mathrm{g} / \mathrm{mL}$ HSA or shCD6 (left) were then subjected to flow cytometry analysis for surface LAP expression. percentage (\%) and geometric mean fluorescence intensity (GM) of $L A P^{+}$Treg cells is shown (middle and right, respectively). ${ }^{*} \mathrm{p}<0.05 ;{ }^{* *} \mathrm{p}<0.01$; ${ }_{* * \star} \mathrm{p}<0.001$; two-tailed Student's t-test.
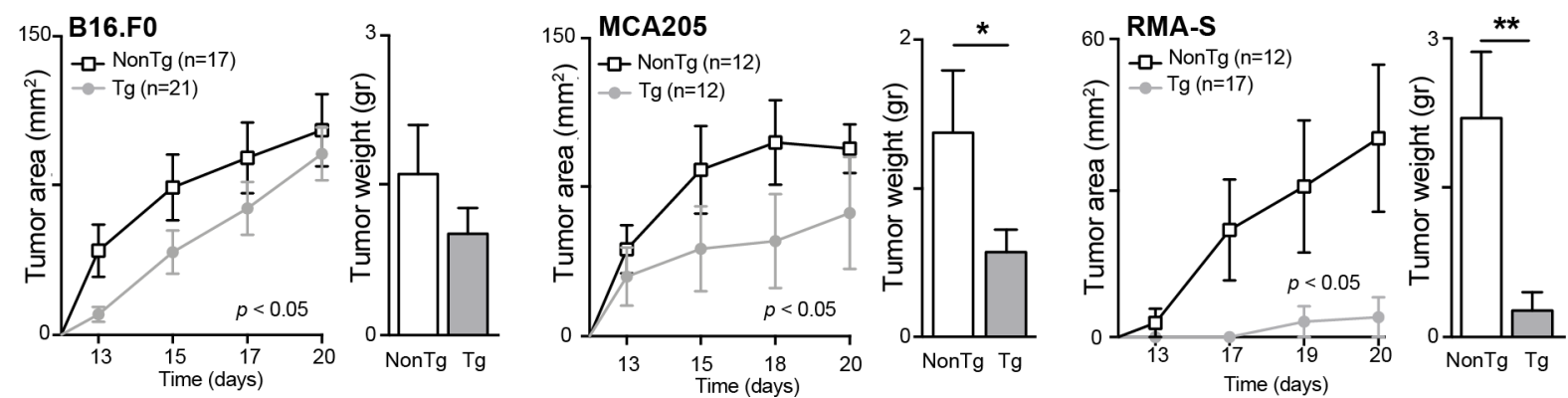

Figure 3 Growth curves of subcutaneously implanted syngeneic cancer cells in shCD6LckE $\mu$ Tg mice. B16.F0 $\left(5 \times 10^{4}\right)$, MCA205 $\left(5 \times 10^{4}\right)$ and RMA-S $\left(2.5 \times 10^{4}\right)$ cells were injected subcutaneously into shCD6LckE $\mu$ Tg and non-transgenic (NonTg) mice. Tumor growth (area in $\mathrm{mm}^{2}$ ) and weight (GR) were measured every other day and at sacrifice, respectively. Cumulative data from two or three independent experiments are represented. Two-way analysis of variance and Mann-Whitney tests were used for statistical analysis of tumor growth and weight, respectively. Data are presented as mean \pm SEM. 

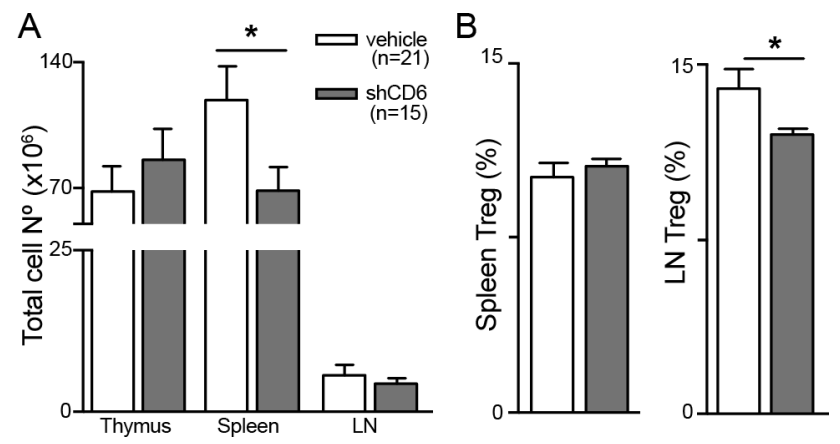

Figure 4 Immunophenotypical analysis of lymphoid organs from wild-type (WT) mice infused with recombinant soluble human CD6 (shCD6) protein. (A) Total lymphoid cell numbers in thymus, spleen, lymph node (LN) and peritoneum of WT mice after intraperitoneal administration of shCD6 (1.25 mg/ $\mathrm{kg}$ ) or vehicle (PBS 10\% glycerol) every 48 hours for 14 days. (B) Percentage of $\mathrm{CD}^{+} 5^{+} \mathrm{FoxP}^{+}$in gated $\mathrm{CD}^{+} \mathrm{T}$ cells (Treg) from spleen and $L N$ of same mice as in $(A)$ is shown. Data represent cumulative results from two independent experiments expressed as mean \pm SEM. ${ }^{*} \mathrm{p}<0.05$; two-tailed Student's t-test.

shCD6-treated mice were challenged with MCA205, EL-4 or RMA-S cells (figure 5), indicating a role for circulating shCD6 in delayed tumor growth in shCD6LckE $\mu$ Tg mice in vivo.

As an approximation to clinical conditions, we explored the effect of every-other-day shCD6 infusion to WT mice bearing 5-9 $\mathrm{mm}^{2}$ B16.F0 tumors ( day 9 post subcutaneous implantation). Again, reduced B16.F0 tumor growth was observed in mice therapeutically treated with shCD6 protein (online supplementary figure S4).
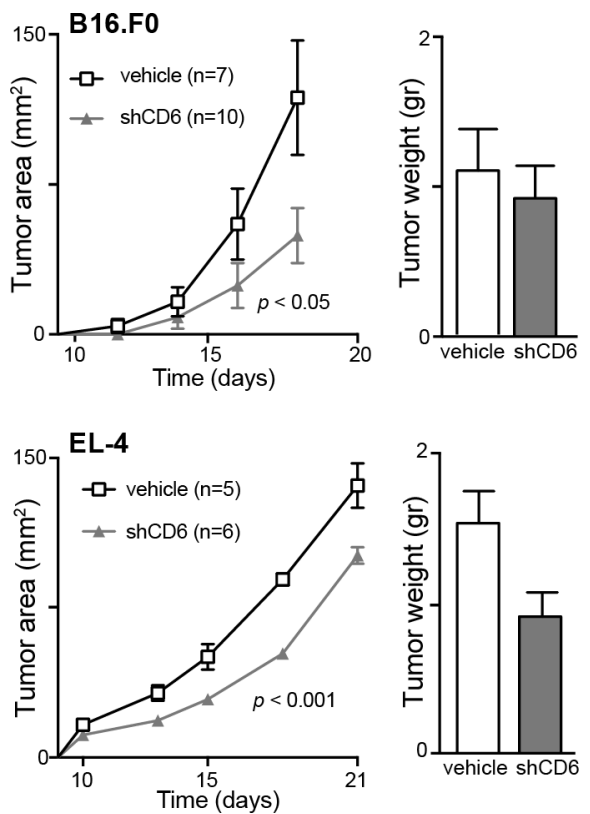

AAV-mediated gene transfer of soluble mouse CD6 (smCD6) leads to reduced metastasis

The antitumor responses of WT mice transduced with hepatotropic AAV for sustained circulating smCD6 protein levels were next explored. Previous data from our group show that AAV-smCD6 transduced WT mice present detectable smCD6 levels from day 10 on, which peak at days 15 to 20 , and remain sustained for longer than 3 months. ${ }^{23}$ We reasoned that smCD6 would be less immunogenic than shCD6 in mice and its long-term expression and function would not be impaired by newly appearing neutralizing antibodies. Mice transduced with optimal AAV-smCD6 doses (10 11 viral genome (v.g.)/mouse), as determined by dose-response experiments (online supplementary figure S5A), do not displayed delayed growth of subcutaneously implanted B16.F0 tumors compared with control mice (AAV-Luc) (figure 6A). In contrast, significantly lower number of lung metastases and improved survival was observed when AAV-smCD6treated mice were challenged intravenously (tail vein) with B16.F0 cells (figure $6 \mathrm{~B}$ and $\mathrm{C}$ ). As illustrated in figure $6 \mathrm{D}$, the effects of AAV-smCD6 mouse transduction on lung metastatization were dose-dependent, with optimal results at $10^{11} \mathrm{v} . \mathrm{g} . /$ mouse. AAV-smCD6 treatment also resulted in reduced numbers of liver metastases when B16.F0 cells were injected into spleen (online supplementary figure S5B).

The possibility that AAV-mediated effects could be in part responsible for the reduced metastatization observed was further ruled out by performing lung metastases assays in which only purified sCD6 protein was infused. In order
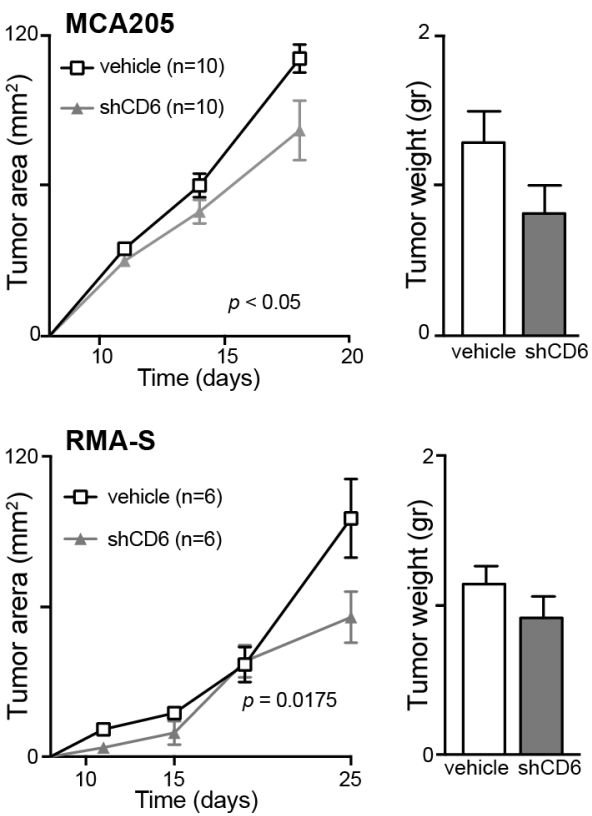

Figure 5 Growth curves of subcutaneously implanted syngeneic cancer cells into wild-type (WT) mice prophylactically infused with soluble human CD6 (shCD6) protein. B16.F0 $\left(5 \times 10^{4}\right)$, MCA205 $\left(5 \times 10^{4}\right)$, EL-4 $\left(5 \times 10^{4}\right)$, and RMA-S $\left(5 \times 10^{4}\right)$ cells were subcutaneously injected into WT mice receiving intraperitoneal injections of shCD6 (1.25 mg/kg) or vehicle (PBS 10\% glycerol) every other day from tumor implantation. Tumor growth (area in $\mathrm{mm}^{2}$ ) and weight (GR) were measured every other day and at sacrifice, respectively. Two-way analysis of variance and Mann-Whitney tests were used for statistical analysis of tumor growth and weight, respectively. Data are presented as mean \pm SE. 

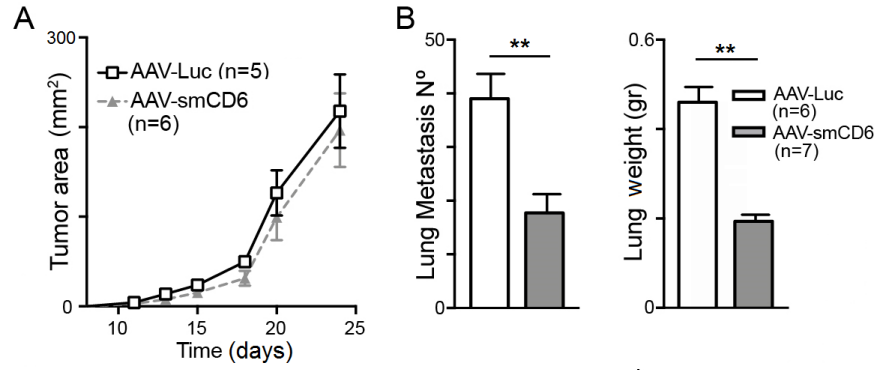

C
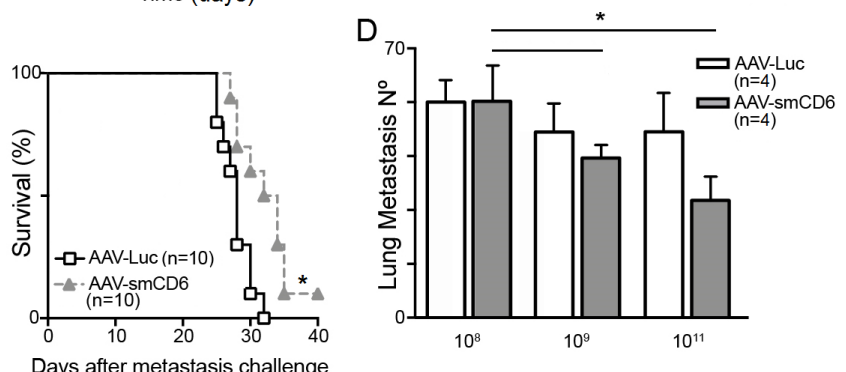

Figure 6 Local growth and metastatization of B16.F0 cells in wild-type (WT) mice transduced with adeno-associated virus (AAV) encoding smCD6 protein. (A) C57BL/6J mice administered viral genome with $10^{11}$ AAV-smCD6 or AAV-Luc viral genome (v.g.)/mouse were challenged 2 weeks later with subcutaneous B16.F0 $\left(5 \times 10^{4}\right)$ cells. Tumor area $\left(\mathrm{mm}^{2}\right)$ monitored twice a week is represented. (B) C57BL/6J mice administered intravenously with $10^{11}$ AAV-smCD6 or AAV-Luc v.g./mouse were challenged intravenously (tail vein) 2 weeks later with B16.F0 $\left(2 \times 10^{5}\right)$ cells. Number of lung metastasis and lung weight (GR) was determined 3 weeks after challenge. (C) Kaplan-Meier survival curve of an independent experiment performed under the same conditions as in (B). (D) C57BL/6J mice transduced intravenously with $10^{8}, 10^{9}$, $10^{11}$ AAV-smCD6 or AAV-Luc v.g./mouse were challenged 2 weeks later with B16.F0 $\left(2 \times 10^{5}\right)$ cells intravenously injected in the tail. Number of lung metastasis determined 3 weeks after challenge is represented. All data represent cumulative results from two independent experiments expressed as mean \pm SEM. ${ }^{\star} p<0.05 ;{ }^{* *} p<0.01$; two-tailed Student's t-test.

to reproduce as much as possible the conditions used in the AAV experiments (prophylactic mode and high circulating sCD6 levels), WT mice were infused intraperitoneally with $1.25 \mathrm{mg} / \mathrm{kg}$ shCD6 or HSA 1 hour before and after intravenous challenge with $2 \times 10^{5}$ B16.F0 cells preincubated for 15 min with shCD6 or HSA. Under such experimental conditions, lower number of lung metastases was observed in shCD6-treated mice compared with HSA-treated controls (online supplementary figure S6).

\section{shCD6 protein reduces in vitro galectin-induced T-cell apoptosis and tumor cell growth and migration}

Abnormal tumor expression of Gal-1 and/or Gal-3 is known to influence tumor development, progression and metastasis through different mechanisms, one of them involving T-cell apoptosis. ${ }^{30}$ All tumor cell lines used in this work express Gal-1 and/or Gal-3 at different levels, as deduced from mRNA analyses (figure 7A). Since CD6 is also known to interact with Gal- 1 and Gal- $3,{ }^{5}$ the influence of shCD6 on galectin-induced T-cell apoptosis was further investigated. To this end, 72-hour activated spleen $\mathrm{T}$ cells were exposed to GST-Gal-1 and GST-Gal-3 in the presence of increasing concentrations of shCD6 (10 and $20 \mu \mathrm{g}$ / $\mathrm{mL})$. As shown in figure $7 \mathrm{~B}$, dose-dependent reduction in Gal-1 and Gal-3-induced apoptotic T cells was induced by shCD6, indicating that shCD 6 may enhance resistance of tumor-specific effector $\mathrm{T}$ cells to apoptosis mediated by either tumor or stroma cell-derived galectins. ${ }^{31}$

Extensive evidence indicates that ALCAM functions as a risk factor in cancer, with its different functional isoforms (soluble and membrane-bound) correlating with specific clinical outcomes depending on cancer type. ${ }^{32}$ Moreover, the interference of homophilic ALCAM-ALCAM interactions by mAbs or chimeric proteins has been shown to reduce tumor cell growth in vitro and in vivo. ${ }^{27} 3334$ In light of these data, we analyzed the effect of shCD6 on in vitro growth of the tumor cell lines used in this study, which show different surface ALCAM levels (figure 7C and online supplementary figure S7). As illustrated in figure 7D, dose-dependent effects were induced by shCD 6 but not HSA on the proliferation of tumor cell lines expressing higher ALCAM surface levels (B16.F0, EL-4, and MC205) compared with RMA-S cells, whose proliferation remained unaffected. Similar inhibitory effects were observed for shCD6 when B16.F0 cell migration was explored by performing wound healing assays (figure 7E).

\section{DISCUSSION}

Recent preclinical and clinical information is attracting new interest on targeting the CD6 lymphocyte surface receptor for therapeutic purposes. ${ }^{2}{ }^{3}$ Genetically modified mouse models greatly contribute to increase our knowledge on the role of CD6 in vivo, as no human CD6 deficiencies have been reported. Accordingly, recent data from $c d 6^{/-}$mice are uncovering unsuspected CD6 activity in health and disease. ${ }^{782435-37}$ However, gene knockdown results do not always reflect bona fide receptor-ligand interaction blockade. This is well illustrated by the role of ALCAM in neuroinflammation, where alcam $^{-/-}$mice show increased neuroinflammatory responses as opposed to that of mice treated with anti-ALCAM blocking mAbs. ${ }^{38}$ In light of this, we reasoned that a soluble form CD6 acting as a decoy receptor in homotypic and/or heterotypic interactions between known (ALCAM, Gal-1 and Gal-3, and CD318/CDCP1) — and hitherto unknown CD6 ligand/s-would provide further information on CD6ligand interaction blockade in vivo.

Our hypothesis was first tested by analyzing the new shCD6E $\mu$ LckTg transgenic mouse line. One advantage of such experimental approach is its translatability to the clinical practice by infusion of soluble recombinant forms of the subject receptor. The latter represents our second experimental approach: the treatment of WT animals with repeated infusions of shCD6 protein. Intermittent protein dosage, even if it does not allow for sustained circulating levels, has served us to exclude transgenesis artifacts in our findings using shCD6E $\mu$ LckTg mice. 

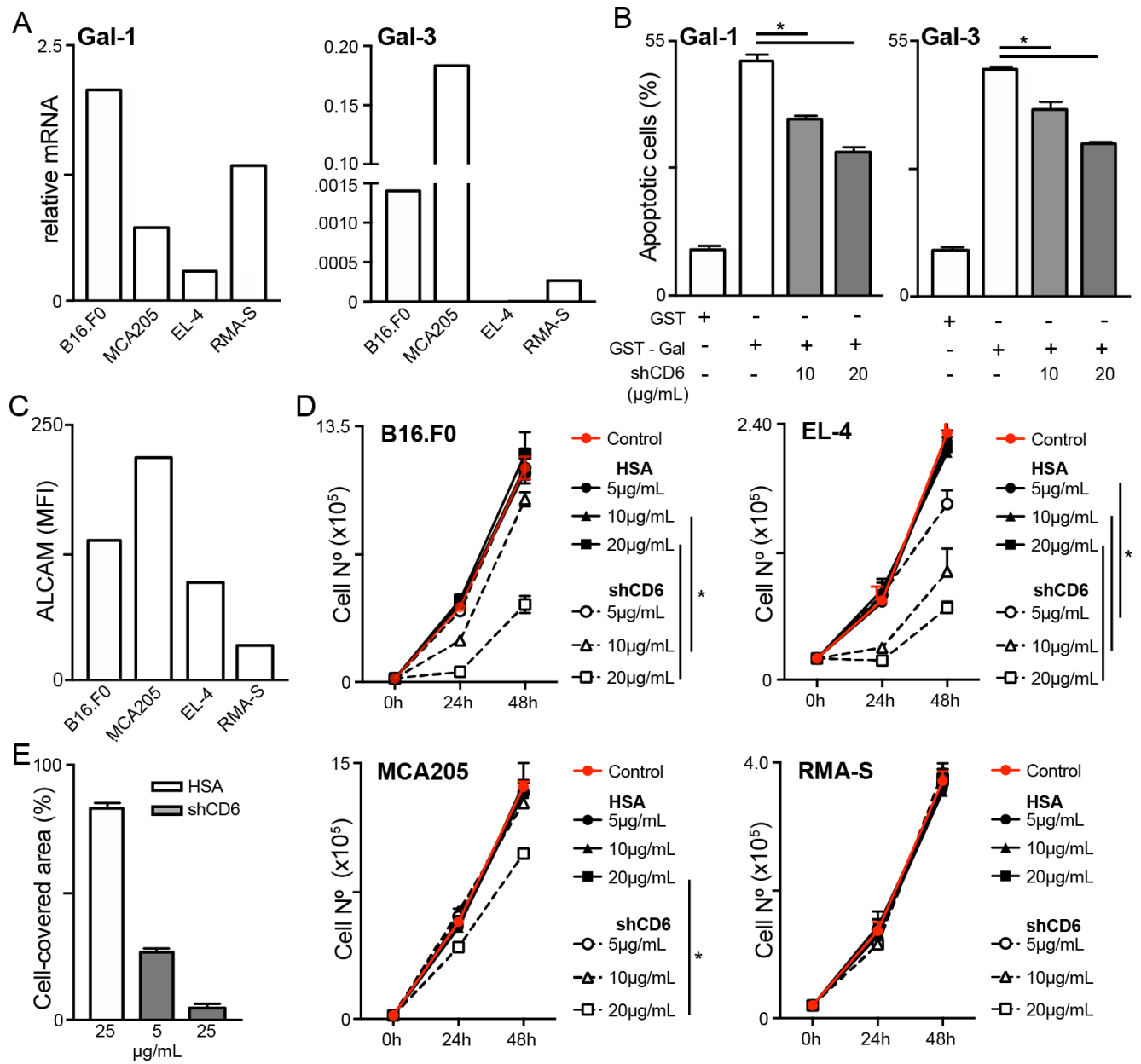

Figure 7 Inhibition of galectin-induced T-cell apoptosis and tumor cell growth and migration by soluble human CD6 (shCD6). (A) Relative Gal-1 and Gal-3 mRNA expression in the different tumor cell lines analyzed in this study, as assessed by qRT-PCR. (B) Splenocytes from wild-type (WT) C57BL/6J mice were activated for 72 hours with anti-CD3 (1 $\mu \mathrm{g} / \mathrm{mL})$ and anti-CD28 $(5 \mu \mathrm{g} /$ $\mathrm{mL}$ ) monoclonal antibodies (mAbs) and then incubated for $30 \mathrm{~min}$ with $100 \mu \mathrm{g} / \mathrm{mL}$ of endotoxin-free glutathione S-transferase (GST), GST-Gal-1 or GST-Gal-3 in the presence of growing concentrations (10 and $20 \mu \mathrm{g} / \mathrm{mL}$ ) of shCD6 protein ( $\mathrm{n}=4 / \mathrm{group}$ ). Percentage of apoptotic cells was determined by flow cytometry. (C) Indicated tumor cells were stained for surface ALCAM expression and mean fluorescence intensity (MFI) was determined by flow cytometry. (D) Tumor cells $\left(2 \times 10^{4}\right)$ were cultured with increasing concentrations (5, 10 and $20 \mu \mathrm{g} / \mathrm{mL} ; \mathrm{n}=4$ /group) of shCD6 or HSA and their numbers counted at 24-hour intervals. (E) Wound healing assays were used to measure the migratory activity of B16.F0 cells $\left(5 \times 10^{5}\right)$ seeded onto 12 -well plates for 24 hours, followed by 2-hour exposure to mitomycin-C $(50 \mu \mathrm{g} / \mathrm{mL})$ and further 12-hour incubation with increasing concentrations ( 5 and $25 \mu \mathrm{g} / \mathrm{mL}$ ) of shCD6 ( $n=4 / g r o u p)$ or HSA control $(n=3)$. Data represent percentage of cell-covered area. In all cases, cumulative results from two independent experiments expressed as mean \pm SEM are presented. * $p<0.05$; two-tailed Student's t-test. ALCAM, activated leukocyte cell adhesion molecule; HSA, human serum albumin.

The immunophenotypical analysis of primary lymphoid organs from shCD6E $\mu \mathrm{LckTg}$ mice under disease-free conditions did not reveal gross alterations. The only noteworthy finding was an increased frequency of DN and CD8SP thymocytes in conjunction with non-significant reductions in that of DP and CD4SP. This indicates that effective interaction between CD6 and its ligand/s expressed on the surface of developing thymocytes and/ or thymic stromal cells (ie, ALCAM) would favor progression from DN to DP developmental stage, and limit that of DP to CD8SP. Interestingly, this thymic phenotype does not match the results from $c d 6^{-}$C57BL/6 mice, where an increased frequency of DP undergoing selection concomitant with reduction in recently selected CD4SP and CD8SP thymocytes is observed. ${ }^{7}$ The disparity between shCD6E $\mu$ LckTg and $c d 6^{--}$mice could relate to the inability of the latter to (1) interact with CD6 ligand/s and (2) transduce ligand-independent intracellular signals.

The immunophenotypical analysis of secondary lymphoid organs from shCD6E $\mu$ LckTg mice revealed decreased total cell numbers in both spleen and LN, while this was only observed in spleens from shCD6treated mice. This could be ascribed to a decrease in the in vivo homeostatic proliferative capability of mainly B cells. This again contrasts with analyses performed with $c d 6^{-}$C57BL/ 6 mice, which revealed no reductions in total cell numbers from spleen and LN, and no defects in B cell proliferative responses in vitro. ${ }^{7}$ However, significantly decreased B1a cell population has been reported 
$c d 6^{/-}$mice of DBA/1 background. ${ }^{36}$ The fact that B cells (in contrast to $\mathrm{T}$ cells) constitutively express ALCAM $^{39}$ and that ALCAM-mediated cell-to-cell homotypic interaction is necessary to sustain proper proliferative responses in different cell types ${ }^{40-42}$ may be behind our observations.

A relevant finding was the reduced frequency of Treg cells in peripheral lymphoid organs from shCD6E $\mu \mathrm{LckTg}$ and shCD6-treated mice, which also showed decreased suppressive activity in vitro. In vitro polarization experiments of naive $\mathrm{CD}^{+} \mathrm{T}$ cells from WT mice confirmed that shCD6 reduces the frequency and functionality of Treg cells, contrary to observations from $c d 6^{/-} \mathrm{C} 57 \mathrm{BL} / 6$ mice, which show increased frequency of peripheral Treg with lower suppressive activity. ${ }^{7}$ Since Treg cell function has been linked to SLP-76-mediated signaling ${ }^{43} 44$ and CD6 constitutes a key element of the SLP-76 interactome ${ }^{434}$ inappropriate recruitment of SLP-76 may be behind the Treg observations made in shCD6E $\mu$ LckTg and shCD6treated mice.

The functional relevance of the inmunophenotypical changes detected in shCD6E $\mu$ LckTg mice was explored by subcutaneous challenge with different syngeneic tumor cell lines. In all cases, tumor growth was significantly decreased in the shCD6E $\mu$ LckTg and/or shCD6-treated WT mice. The lower tumor growth in both experimental settings may result from the lower levels of peripheral Treg cells with reduced suppressive activity. However, $c d \sigma$ C57BL/6 mice show increased frequency of dysfunctional Treg cells ${ }^{7}$ but do not significantly differ from WT C57BL/6 mice regarding antitumor responses (online supplementary figure S8). Thus, alternative mechanisms may also contribute to the observed decrease in tumor growth. By using different experimental in vitro systems we demonstrate that shCD6 interferes with certain tumorigenicity-related events such as galectin-induced T-cell apoptosis, and ALCAM-mediated tumor cell proliferation and migration. Indeed, preliminary experiments with patient-derived melanoma cells (A375) engrafted into immunocompromised NSG mice indicate that shCD6 effects do not require a fully preserved immune system (online supplementary figure S9).

Galectins (namely, Gal-1 and Gal-3) are overexpressed in a broad range of cancers (by both stromal or malignant cells) and known to induce T-cell apoptosis contributing to immunosuppression within the tumor microenvironment. ${ }^{31} 45-47$ The tumorigenic properties of galectins are, however, not limited to immunosuppression but to promotion of cancer cell proliferation, migration, and invasion, ${ }^{47}$ which could be also interfered by shCD6.

The most membrane-proximal SRCR ectodomain of CD6 (D3) is directly involved in the interaction with ALCAM. ${ }^{15} 16$ This heterophilic interaction is conserved across species and competes with homophilic ALCAM interactions due to its higher binding affinity. ${ }^{1315}$ ALCAM overexpression has been detected in numerous malignancies (eg, melanoma, gastric cancer, esophageal squamous cell carcinoma, endometrial cancer, lung cancer, and pancreatic cancer), and relates to poor prognosis, tumor progression, invasion and metastasis. ${ }^{41}{ }^{48-51}$ The contribution of ALCAM to tumor progression through the fine-tuning of homophilic adhesive cell-to-cell interactions between cancer cells and with stromal and/ or endothelial cells has been reported. ${ }^{34}{ }^{48}$ However, heterophilic ALCAM interactions with Gal-1, Gal-3 and Gal- ${ }^{5}{ }^{52}$ or the Ig-like transcript 3 (ILT3) - an inhibitory receptor expressed by cells of myelomonocytic origin and a marker of tolerogenic dendritic cells ${ }^{27}$ - may also play a role. Similar to shCD6, chimeric soluble ILT3 (ILT3.Fc) inhibited in vitro $\mathrm{T}$ cell proliferation and differentiation to Treg, and also tumor cell growth and migration in an ALCAM-dependent manner cells. ${ }^{27}$ These observations support the targeting of ALCAM for immunotherapeutic purposes in cancer. On this basis, we tested the efficacy of sustained smCD6 delivery by means of AAV-based gene transfer-a successful strategy in several preclinical models and in recent clinical cancer trials. ${ }^{53}$ Contrary to expectations, implanted subcutaneous B16.F0 melanoma maintained local tumor growth rates in WT mice previously transduced with either hepatotropic AAV-smCD6 or control AAV-Luc, while lower lung and liver metastatization were observed after intravenous B16.F0 cell infusion of WT mice transduced with AAV-smCD6 v.p. In our view, infection with AAVs triggers a non-specific immuneboosting effect (eg, through innate recognition of viral capsid and DNA) irrespective of shCD6 expression. ${ }^{54}$ This alone reduces local tumor growth, and overshadows the anti-tumor effects of AAV-smCD6. In the metastasis model, the AAV immune-boost is overridden by ALCAMdependence of tumor cell adhesion to endothelia. High circulating smCD6 levels achieved with AAV-smCD6 infection are highly effective in that regard, highlighting its role in metastasis prevention.

A general concern with therapeutic approaches that potentiate antitumor responses is the development of autoimmunity as a secondary effect. Preliminary results addressed to assess potential autoimmune responses generated by shCD6 show that shCD6E $\mu$ LckTg mice present a less severe outcome in two different models of induced autoimmune disease (collagen-induced aArthritis, CIA; experimental autoimmune encephalitis, EAE), compared with NonTg controls (online supplementary figure S10A and S10B). Importantly, a similar attenuated autoimmune disease was observed when WT mice were infused every other day with recombinant shCD6 from day 0 of EAE induction (online supplementary figure S10C). These results are in line with published data showing attenuated EAE disease severity in $c d 6^{-/-}$mice of DBA/1 and C57BL/6 background and in CD6 humanized mice treated with a non-depleting mouse anti-human CD6 mAb. ${ }^{85}$ The beneficial effect of a shCD6 decoy receptor on both tumor and autoimmune contexts may relate to (1) differences in their respective pathophysiological effectors, and/or (2) the multiligand properties of $\mathrm{CD} 6$, since drivers of tumorigenic microenvironment in cancer such as galectins and ALCAM are also known to favor autoimmune inflammation. ${ }^{39} 56$ 


\section{CONCLUSIONS}

In summary, the shCD6E $\mu$ LckTg model reveals novel therapeutic potential of impairing CD6-ligand/s interaction/s by infusion of shCD6 protein. Enhancement of antitumor responses following ALCAM blockade with single chain fragment variable $(\mathrm{scFv})$ fragments or whole antibodies has been reported to disturb cell-tocell and cell-extracellular matrix interactions important for primary tumor growth and/or leukocyte trafficking (including that of Treg cells). ${ }^{33} 3957$ These mechanisms may also explain the therapeutic effects we report for shCD6 as a proof-of-concept. Future studies are required to reveal the full immunotherapeutic applications of shCD6 in relevant human disorders.

\section{Author affiliations}

${ }^{1}$ Immunoreceptors del Sistema Innat i Adaptatiu, Institut d'Investigacions Biomediques August Pi i Sunyer, Barcelona, Catalunya, Spain

${ }^{2}$ Departamento de Biología Molecular, Universidad de Cantabria-IDIVAL, Santander, Cantabria, Spain

${ }^{3}$ Instituto de Biomedicina y Biotecnología de Cantabria, CSIC-UC, Santander, Cantabria, Spain

${ }^{4}$ Arthritis and Clinical Immunology Program, Oklahoma Medical Research Foundation, Oklahoma City, Oklahoma, USA

${ }^{5}$ Gene Therapy and Regulation of Gene Expression Program, Universidad de Navarra, Pamplona, Navarra, Spain

${ }^{6}$ Departament de Biomedicina, Facultat de Medicina, Universitat de Barcelona,

Barcelona, Barcelona, Spain

${ }^{7}$ Servei d'Immunologia, Hospital Clínic de Barcelona, Barcelona, Spain

Acknowledgements We thank Marcos Isamat for critically reviewing the manuscript and Francisco Simões for graphics editing.

Contributors ITS, FA, SC-L, MV-dA, CC, PA, MC-F, MO-M, EC, and VM performed the experiments. ITS, FA, VM, and FL wrote the paper. FA, RM, JM, GG-A, JA-I, EC, VM, and FL designed and supervised the project. All authors discussed the results, participated in writing the paper and approved the final manuscript.

Funding This work was supported by the Worldwide Cancer Research (14-1275), Fundació La Marató TV3 (201319-30), and Ministerio de Economía y Competitividad (SAF-2016-80535-R) co-financed by European Development Regional Fund 'A way to achieve Europe' ERDF to FL; SAF2016-75195-R to JM, SAF2017-82905-R to RM, and SAF2015-70028-R to GG-A. ITS, MO-M, MV-dA, CC, SC-L and FA are recipients of fellowships from Fundação para a Ciência e a Tecnologia (SFRH/ BD/75738/2011), Ministerio de Economía y Competitividad (BES-2011-048415; BES-2014-069237; BES-2017-082107), Ministerio de Educación Cultura y Deporte (FPU15/02897), and Instituto de Salud Carlos III (Sara Borrell Programme, CD15/00016), respectively.

Competing interests None declared.

\section{Patient consent for publication Not required.}

Ethics approval The experimental protocols used were approved by the Ethics Committee for Animal Research of the University of Barcelona (permit numbers 54/16, 740/14, 741/14, and 742/14).

Provenance and peer review Not commissioned; externally peer reviewed.

Data availability statement All data relevant to the study are included in the article or uploaded as supplementary information.

Open access This is an open access article distributed in accordance with the Creative Commons Attribution Non Commercial (CC BY-NC 4.0) license, which permits others to distribute, remix, adapt, build upon this work noncommercially, and license their derivative works on different terms, provided the original work is properly cited, appropriate credit is given, any changes made indicated, and the use is non-commercial. See http://creativecommons.org/ licenses/by-nc/4.0/.

\section{ORCID iD}

Francisco Lozano http://orcid.org/0000-0003-1119-4368

\section{REFERENCES}

1 Dustin ML. The immunological synapse. Cancer Immunol Res 2014;2:1023-33.

2 Consuegra-Fernández M, Lin F, Fox DA, et al. Clinical and experimental evidence for targeting CD6 in immune-based disorders. Autoimmun Rev 2018;17:493-503.

3 Hernández P, Moreno E, E. Aira L, et al. Therapeutic targeting of CD6 in autoimmune diseases: a review of Cuban clinical studies with the antibodies IOR-T1 and Itolizumab. Curr Drug Targets 2016;17:666-77.

4 Bowen MA, Patel DD, Li X, et al. Cloning, mapping, and characterization of activated leukocyte-cell adhesion molecule (ALCAM), a CD6 ligand. J Exp Med 1995;181:2213-20.

5 Escoda-Ferran C, Carrasco E, Caballero-Baños M, et al. Modulation of CD6 function through interaction with galectin-1 and -3. FEBS Lett 2014;588:2805-13.

6 Enyindah-Asonye G, Li Y, Ruth JH, et al. CD318 is a ligand for CD6. Proc Natl Acad Sci U S A 2017;114:E6912-21.

7 Orta-Mascaró M, Consuegra-Fernández M, Carreras E, et al. Cd6 modulates thymocyte selection and peripheral T cell homeostasis. $J$ Exp Med 2016;213:1387-97.

8 Li Y, Singer NG, Whitbred J, et al. Cd6 as a potential target for treating multiple sclerosis. Proc Natl Acad Sci U S A 2017;114:2687-92.

9 Carrasco E, Escoda-Ferran C, Climent N, et al. Human CD6 downmodulation following T-cell activation compromises lymphocyte survival and proliferative responses. Front Immunol 2017;8:769.

10 Ramos-Casals M, Font J, Garcı M, et al. High circulating levels of soluble scavenger receptors (sCD5 and SCD6) in patients with primary Sjögren's syndrome. Arthritis Rheum 2001;40:1056-9.

11 Aibar J, Martínez-Florensa M, Castro P, et al. Pattern of soluble CD5 and CD6 lymphocyte receptors in critically ill patients with septic syndromes. J Crit Care 2015;30:914-9.

12 Gimferrer I, Calvo M, Mittelbrunn M, et al. Relevance of CD6mediated interactions in T cell activation and proliferation. J Immunol 2004;173:2262-70.

13 Hassan NJ, Barclay AN, Brown MH. Frontline: optimal T cell activation requires the engagement of CD6 and CD166. Eur J Immunol 2004;34:930-40.

14 Zimmerman AW, Joosten B, Torensma R, et al. Long-Term engagement of CD6 and ALCAM is essential for T-cell proliferation induced by dendritic cells. Blood 2006;107:3212-20.

15 Bowen MA, Bajorath J, D'egidio M, et al. Characterization of mouse ALCAM (CD166): the CD6-binding domain is conserved in different homologs and mediates cross-species binding. Eur J Immunol 1997;27:1469-78.

16 Chappell PE, Garner LI, Yan J, et al. Structures of CD6 and its ligand CD166 give insight into their interaction. Structure 2015;23:1426-36.

17 Iritani BM, Forbush KA, Farrar MA. Control of B cell development by Ras-mediated activation of Raf. Embo J 1997;16:7019-31.

18 Ronchese F, Hausmann B, Hubele S, et al. Mice transgenic for a soluble form of murine CTLA-4 show enhanced expansion of antigen-specific CD4+ T cells and defective antibody production in vivo. J Exp Med 1994;179:809-17.

19 Peters M, Jacobs S, Ehlers M, et al. The function of the soluble interleukin 6 (IL-6) receptor in vivo: sensitization of human soluble IL-6 receptor transgenic mice towards IL- 6 and prolongation of the plasma half-life of IL-6. J Exp Med 1996;183:1399-406.

20 Hunger RE, Carnaud C, Garcia I, et al. Prevention of autoimmune diabetes mellitus in NOD mice by transgenic expression of soluble tumor necrosis factor receptor p55. Eur J Immunol 1997;27:255-61.

21 Tamura Y, Higuchi Y, Kataoka M, et al. Cd14 transgenic mice expressing membrane and soluble forms: comparisons of levels of cytokines and lethalities in response to lipopolysaccharide between transgenic and non-transgenic mice. Int Immunol 1999;11:333-9.

22 Bao L, Haas M, Boackle SA, et al. Transgenic Expression of a Soluble Complement Inhibitor Protects Against Renal Disease and Promotes Survival in MRL/ Ipr Mice. J Immunol 2002;168:3601-7.

23 Martínez-Florensa M, Consuegra-Fernández M, Aranda F, et al. Protective effects of human and mouse soluble scavenger-like CD6 lymphocyte receptor in a lethal model of polymicrobial sepsis. Antimicrob Agents Chemother 2017;61:e01391-16.

24 Consuegra-Fernández M, Martínez-Florensa M, Aranda F, et al. Relevance of CD6-Mediated interactions in the regulation of peripheral T-cell responses and tolerance. Front Immunol 2017;8:594.

25 Simões IT, Aranda F, Carreras E, et al. Immunomodulatory effects of soluble CD5 on experimental tumor models. Oncotarget 2017;8:108156-69. 
26 Timmons JJ, Cohessy S, Wong ET. Injection of syngeneic murine melanoma cells to determine their metastatic potential in the lungs. $J$ Vis Exp 2016;111:e54039.

27 Xu Z, Chang C-C, Li M, et al. ILT3.Fc-CD166 interaction induces inactivation of p70 S6 kinase and inhibits tumor cell growth. J.i. 2018;200:1207-19.

28 Maes H, Van Eygen S, Krysko DV, et al. Bnip3 supports melanoma cell migration and vasculogenic mimicry by orchestrating the actin cytoskeleton. Cell Death Dis 2014;5:e1127.

29 Tran DQ, Andersson J, Hardwick D, et al. Selective expression of latency-associated peptide (LAP) and IL-1 receptor type I/II (CD121a/ CD121b) on activated human Foxp3+ regulatory $T$ cells allows for their purification from expansion cultures. Blood 2009;113:5125-33.

30 Chou F-C, Chen H-Y, Kuo C-C, et al. Role of galectins in tumors and in clinical immunotherapy. Int J Mol Sci 2018;19:430.

31 Orozco CA, Martinez-Bosch N, Guerrero PE, et al. Targeting galectin-1 inhibits pancreatic cancer progression by modulating tumor-stroma crosstalk. Proc Natl Acad Sci U S A 2018;115:E3769-78.

32 Xiao M, Wang X, Yan M, et al. A systematic evaluation for the potential translation of CD166-related expression as a cancer biomarker. Expert Rev Mol Diagn 2016;16:925-32.

33 Wiiger MT, Gehrken HB, Fodstad Øystein, et al. A novel human recombinant single-chain antibody targeting CD166/ALCAM inhibits cancer cell invasion in vitro and in vivo tumour growth. Cancer Immunol Immunother 2010;59:1665-74.

34 von Lersner A, Droesen L, Zijlstra A. Modulation of cell adhesion and migration through regulation of the immunoglobulin superfamily member ALCAM/CD166. Clin Exp Metastasis 2019;36:87-95.

35 Enyindah-Asonye G, Li Y, Xin W, et al. Cd6 receptor regulates intestinal ischemia/reperfusion-induced injury by modulating natural IgM-producing B1a cell self-renewal. J. Biol. Chem. 2017;292:661-71.

36 Consuegra-Fernández $\mathrm{M}$, Julià $\mathrm{M}$, Martínez-Florensa $\mathrm{M}$, et al. Genetic and experimental evidence for the involvement of the CD6 lymphocyte receptor in psoriasis. Cell Mol Immunol 2018;15:898-906

37 Zhang L, Li Y, Qiu W, et al. Targeting CD6 for the treatment of experimental autoimmune uveitis. J Autoimmun 2018;90:84-93.

38 Lécuyer M-A, Saint-Laurent O, Bourbonnière L, et al. Dual role of ALCAM in neuroinflammation and blood-brain barrier homeostasis. Proc Natl Acad Sci U S A 2017;114:E524-33.

39 Cayrol R, Wosik K, Berard JL, et al. Activated leukocyte cell adhesion molecule promotes leukocyte trafficking into the central nervous system. Nat Immunol 2008;9:137-45.

40 Hansen AG, Arnold SA, Jiang M, et al. ALCAM/CD166 Is a TGF-Responsive Marker and Functional Regulator of Prostate Cancer Metastasis to Bone. Cancer Res 2014;74:1404-15.

41 Fujiwara K, Ohuchida K, Sada M, et al. CD166/ALCAM expression is characteristic of tumorigenicity and invasive and migratory activities of pancreatic cancer cells. PLoS One 2014;9:e107247.
42 Yu W, Wang J, Ma L, et al. Cd166 plays a pro-carcinogenic role in liver cancer cells via inhibition of FOXO proteins through Akt. Oncol Rep 2014;32:677-83.

43 Schmidt AM, Lu W, Sindhava VJ, et al. Regulatory T cells require TCR signaling for their suppressive function. J.i. 2015;194:4362-70.

44 Roncagalli R, Hauri S, Fiore F, et al. Quantitative proteomics analysis of signalosome dynamics in primary $\mathrm{T}$ cells identifies the surface receptor CD6 as a LAT adaptor-independent TCR signaling hub. Nat Immunol 2014;15:384-92.

45 Rubinstein N, Alvarez M, Zwirner NW, et al. Targeted inhibition of galectin-1 gene expression in tumor cells results in heightened T cell-mediated rejection; a potential mechanism of tumor-immune privilege. Cancer Cell 2004;5:241-51.

46 Tang D, Gao J, Wang S, et al. Apoptosis and anergy of T cell induced by pancreatic stellate cells-derived galectin-1 in pancreatic cancer. Tumor Biol. 2015;36:5617-26.

47 Farhad M, Rolig AS, Redmond WL. The role of galectin-3 in modulating tumor growth and immunosuppression within the tumor microenvironment. Oncoimmunology 2018;7:e1434467.

48 Willrodt $\mathrm{A}-\mathrm{H}$, Beffinger M, Vranova $\mathrm{M}$, et al. Stromal expression of activated leukocyte cell adhesion molecule promotes lung tumor growth and metastasis. Am J Pathol 2017;187:2558-69.

49 Jannie KM, Stipp CS, Weiner JA. Alcam regulates motility, invasiveness, and adherens junction formation in uveal melanoma cells. PLoS One 2012; 7:e39330.

50 Ye M, Du Y-L, Nie Y-Q, et al. Overexpression of activated leukocute cell adhesion molecule in gastric cancer is associated with advanced stages and poor prognosis and miR-9 deregulation. Mol Med Rep 2015;11:2004-12.

51 Tachezy M, Effenberger K, Zander H, et al. Alcam (CD166) expression and serum levels are markers for poor survival of esophageal cancer patients. Int. J. Cancer 2012;131:396-405.

52 Ferragut F, Cagnoni AJ, Colombo LL, et al. Dual knockdown of galectin-8 and its glycosylated ligand, the activated leukocyte cell adhesion molecule (ALCAM/CD166), synergistically delays in vivo breast cancer growth. Biochim Biophys Acta - Mol Cell Res 2019;1866:1338-52.

53 Santiago-Ortiz JL, Schaffer DV. Adeno-Associated virus (AAV) vectors in cancer gene therapy. J Control Release 2016;240:287-301.

54 Basner-Tschakarjan E, Mingozzi F. Cell-Mediated immunity to AAV vectors, evolving concepts and potential solutions. Front Immunol 2014;5:350.

55 Consuegra-Fernández M, Isamat M, Lozano F. Commentary: CD6 as a potential target for treating multiple sclerosis. Front Immunol 2017:8:1217.

56 Toscano MA, Martínez Allo VC, Cutine AM, et al. Untangling Galectindriven regulatory circuits in autoimmune inflammation. Trends $\mathrm{Mol}$ Med 2018;24:348-63.

57 Nummer D, Suri-Payer E, Schmitz-Winnenthal $\mathrm{H}$, et al. Role of tumor endothelium in CD4+CD25+ regulatory T cell infiltration of human pancreatic carcinoma. J Natl Cancer Inst 2007;99:1188-99. 